\title{
BMJ Open Risk perception, beliefs about medicines and medical adherence among pregnant and breastfeeding women with migraine: findings from a cross-sectional study in Norway
}

Siri Amundsen, ${ }^{1,2}$ Torunn Gudmestad $\varnothing v$ rebø, ${ }^{3}$ Netta Marie Skretteberg Amble, ${ }^{3}$ Anne Christine Poole, ${ }^{4}$ Hedvig Nordeng ${ }^{3}$

To cite: Amundsen $\mathrm{S}$, $\emptyset$ vrebø TG, Amble NMS, et al. Risk perception, beliefs about medicines and medical adherence among pregnant and breastfeeding women with migraine: findings from a cross-sectional study in Norway. BMJ Open 2019;9:e026690. doi:10.1136/ bmjopen-2018-026690

- Prepublication history and additional material for this paper are available online. To view these files, please visit the journal online (http://dx. doi org/10.1136/bmjopen-2018026690).

Received 14 September 2018 Revised 10 December 2018 Accepted 2 January 2019

\section{Check for updates}

C Author(s) (or their employer(s)) 2019. Re-use permitted under CC BY-NC. No commercial re-use. See rights and permissions. Published by BMJ.

${ }^{1}$ Department of Laboratory Medicine, University Hospital of North Norway, Troms $\emptyset$, Norway

${ }^{2}$ Department of Medical Biology, Faculty of Health Sciences, UiT The Arctic University of Norway, Tromsø, Norway

${ }^{3}$ Department of Pharmacy, University of Oslo, Oslo, Norway ${ }^{4}$ Volvat Medical Centre, Oslo, Norway

Correspondence to

Siri Amundsen;

siri.amundsen@unn.no

\section{ABSTRACT}

Objectives To examine risk perception, beliefs about migraine medications and medical adherence among pregnant and breastfeeding women with migraine. Design and setting Cross-sectional study conducted in Norway from October 2013 to February 2014. Data were collected via an anonymous, electronic questionnaire. Participants Women with migraine, either pregnant or having delivered within the previous 18 months.

Main outcomes Women's perception of teratogenic risk (numeric rating scale 0-10) was obtained for 14 different drugs/substances, including medications commonly used in the acute treatment of migraine. Women's perspectives on migraine drug therapy were assessed by 10 statements from the Beliefs about Medicines Questionnaire (BMQSpecific) and six pregnancy/breastfeeding-specific statements. Adherence to migraine treatment during pregnancy and breastfeeding period was assessed by maternal self-report.

Results The study population included 401 women with migraine, of which 140 were pregnant and 261 were new mothers. More than $70 \%$ of the women reported use of migraine medications during pregnancy. Still, the majority severely overestimated the risk associated with migraine medications and were concerned about using medications to manage their migraine during pregnancy and breastfeeding. Almost 9 out of 10 women had at some point deliberately avoided using migraine medications during their pregnancy. Women reporting use of migraine medications, however, were more positive and overestimated to a lesser extent the risks of using such medications in pregnancy compared with their counterparts.

Conclusions Women with migraine severely overestimated the risk associated with migraine pharmacotherapy in pregnancy. The majority of women were concerned about use of migraine medications during pregnancy and breastfeeding and reported non-adherence to needed treatment. More attention should be focused on women's beliefs and concerns regarding migraine pharmacotherapy during pregnancy and breastfeeding in order to improve management of disease, reduce unfounded concerns and enhance adherence to needed treatment.

\section{Strengths and limitations of this study}

- First study to explore risk perception, beliefs about migraine medications and medical adherence in pregnant and breastfeeding women with migraine.

- Women's own perspectives on management of migraine during pregnancy and breastfeeding may help healthcare professionals better understand the impact of the disease and how to provide optimal healthcare to this patient group.

- Studies using electronic questionnaires carry a potential risk of selection bias towards the more literate population. However, using the internet for recruitment and data collection enabled us to reach women with migraine nationwide.

- The validity of self-reported data relies on the accuracy of respondents' recall.

\section{INTRODUCTION}

Migraine affects approximately 20\%-25\% of women of childbearing age. ${ }^{1}$ Optimal management of symptoms is a goal in all stages of life, including pregnancy and breastfeeding period. The majority of women with pre-existing migraine experience an improvement, or even complete remission, of symptoms throughout pregnancy. ${ }^{2-4}$ For women with mild symptoms, non-pharmacological approaches may be sufficient, but in patients with more severe migraine, medical treatment is still often required. Previous studies have shown that more than $70 \%$ of women with migraine in pregnancy report use of migraine medications. ${ }^{56}$

Commonly used medications to treat acute migraine attacks include triptans and non-opioid analgesics such as paracetamol and non-steroidal anti-inflammatory drugs (NSAIDs). Paracetamol is considered the safest option during pregnancy and 
breastfeeding and therefore recommended as the drug of first choice for treatment of acute pain. ${ }^{78}$ Nevertheless, many women may need alternative treatment options to manage their migraine sufficiently. As experience with use in pregnancy and during breastfeeding is still limited for many migraine medications, it is often difficult to decide whether maternal benefit of medical treatment outweighs the potential risk to the fetus or breastfed infant.

In order to provide optimal migraine management and counselling to pregnant and breastfeeding women, knowledge about their perceptions and beliefs about migraine medications is necessary. Women's beliefs will likely influence their decision for whether to use a needed medication or not, as indicated by previous studies on medication use among pregnant women. ${ }^{9-12}$ Overall, only a few drugs are proven to have teratogenic effects, and less than $2 \%$ of all birth defects are thought to arise from drug exposure. ${ }^{13}$ However, several studies have demonstrated that pregnant women, ${ }^{14-19}$ and also physicians and other healthcare professionals, ${ }^{18-21}$ tend to overestimate the risks associated with maternal medication use during pregnancy. This misperception may have negative consequences, resulting in suboptimal treatment, discontinuation of needed therapy or even impact womens' decision to terminate a wanted pregnancy. ${ }^{22}$ Evidence-based counselling of pregnant women on the risks and benefit of medical treatment has proved effective in lowering unrealistically high risk perception. ${ }^{1722-24}$

Little attention has been focused on migraine management during pregnancy and breastfeeding from the patients' perspective. The purpose of this study was to explore risk perception, beliefs about migraine medications and adherence to needed treatment among pregnant and breastfeeding women with migraine.

\section{METHODS}

\section{Study design, study population and data collection}

This study is based on data from a cross-sectional study conducted in Norway. Women with migraine, either pregnant at any gestational week or having delivered within the previous 18 months, were eligible to participate. All data were self-reported and collected via an anonymous, electronic questionnaire, accessible online from 1 October 2013 to 1 February 2014. A translated version of the complete questionnaire is presented in a previous publication. ${ }^{25}$ Participants were recruited through advertisements on selected national websites and/or social networks primarily directed at pregnant women and new mothers. The advertisements contained a link to the questionnaire and further information about the study. Information about the selected websites and the recruitment procedure has been described in detail elsewhere. ${ }^{25}$ Women who participated were representative of the general birthing population in Norway with respect to geographical living area. ${ }^{25}$

This paper presents the results covering risk perception, perceived needs and concerns about migraine medications during pregnancy and breastfeeding, and self-reported medical adherence during this period.

\section{Migraine characteristics and use of migraine medication during and after pregnancy}

All participants had to provide detailed information about migraine characteristics including years since onset, type (aura/non-aura), trigger factors, attack frequency and severity of migraine during and after pregnancy. They were asked to report any migraine medication they had used during pregnancy and the breastfeeding period. To enhance recall, the women were presented with a list of 16 commonly used acute migraine medication including analgesics (paracetamol; combinations of paracetamol with codeine and caffeine, respectively; NSAIDs: ibuprofen, naproxen, diclofenac and tolfenamic acid; and phenazone-caffeine); migraine-specific medications (triptans and ergotamine); and antiemetics (metoclopramide). Generic names of the drugs were given in the questionnaire together with their most common trade names. Use of other medications not covered by the list and use of preventive treatment were reported as freetext entry.

\section{Risk perception and beliefs about migraine medication}

Baseline perception of teratogenic risk was assessed by asking the women the following question: 'Among 100 healthy pregnant women, how many do you think will give birth to a child with a severe birth defect?'. The answers were provided as free-text entry. The prevalence of birth defects among all pregnancies is estimated to be $3 \%-4 \%^{26}$; hence this was defined as the 'true' baseline risk. Subsequently, the women were presented a list of 14 drugs and other substances including (1) analgesics and other medications commonly used in acute treatment of migraine (paracetamol, ibuprofen [in third trimester], triptans and metoclopramide); (2) herbal medicines (ie, feverfew); (3) alcohol (in first trimester) and tobacco (smoking); and (4) thalidomide. They were asked to assign risk perception scores ranging from 0 (not harmful) to 10 (very harmful) according to their own perceived risk for the fetus in case of maternal use during pregnancy. In case the substance was unfamiliar to them, they were given the option to answer 'Do not know'.

\section{Beliefs about migraine medication}

Beliefs about migraine medication were examined by using the Beliefs about Medicines Questionnaire (BMQ-Specific). ${ }^{27}$ This is a validated instrument to assess patients' personal views about their medicines. For our study, the wording of the questions was specific for migraine medications. The BMQ-Specific comprises five items assessing beliefs about the necessity of medication to maintain or improve current and future health (Specific-Necessity) and five items assessing concerns about prescribed medication and potential negative effects (Specific-Concerns). For each statement, respondents marked their level of agreement on a 5-point Likert scale ranging from 1 to 
Table 1 Overview of sociodemographic, lifestyle and migraine characteristics of the study population $(n=401)$

\begin{tabular}{|c|c|}
\hline Characteristics & $\mathbf{N}(\%$ of $n)$ \\
\hline \multicolumn{2}{|l|}{ Status of participant } \\
\hline Pregnant & $140(34.9)$ \\
\hline Mother & $261(65.1)$ \\
\hline \multicolumn{2}{|l|}{ Age (years) } \\
\hline$\leq 25$ & 85 (21.2) \\
\hline $26-30$ & $132(32.9)$ \\
\hline $31-35$ & $123(30.7)$ \\
\hline$\geq 36$ & $61(15.2)$ \\
\hline \multicolumn{2}{|l|}{ Marital status } \\
\hline Married/cohabiting & $380(94.8)$ \\
\hline Single/divorced/other & $21(5.2)$ \\
\hline \multicolumn{2}{|l|}{ Education ${ }^{\star}$} \\
\hline Primary/secondary/high school & $115(28.7)$ \\
\hline College/university (1-4 years) & $181(45.1)$ \\
\hline College/university ( $\geq 5$ years) & $105(26.2)$ \\
\hline \multicolumn{2}{|l|}{ Employment } \\
\hline Yes & $320(79.8)$ \\
\hline Not & $8(20.2)$ \\
\hline \multicolumn{2}{|l|}{ Parity } \\
\hline Primiparous $\ddagger$ & 207 (51.6) \\
\hline Multiparous & $194(48.4)$ \\
\hline \multicolumn{2}{|l|}{ Smoking during pregnancy } \\
\hline No & $373(93.0)$ \\
\hline Yes & $28(7.0)$ \\
\hline \multicolumn{2}{|l|}{ Alcohol use during pregnancy§ } \\
\hline No & $390(97.3)$ \\
\hline Yesף & $11(2.7)$ \\
\hline \multicolumn{2}{|l|}{ Migraine type } \\
\hline With aura & $172(42.9)$ \\
\hline Without aura/other & $229(57.1)$ \\
\hline \multicolumn{2}{|l|}{ Years since onset of migraine ${ }^{\star \star}$} \\
\hline$\leq 5$ & $73(18.2)$ \\
\hline $6-15$ & $178(44.4)$ \\
\hline$\geq 16$ & $148(36.9)$ \\
\hline \multicolumn{2}{|c|}{ Migraine medication use during pregnancy } \\
\hline Yes & 294 (73.3) \\
\hline No & $107(26.7)$ \\
\hline
\end{tabular}

Migraine medication use during

breastfeeding period $(\mathrm{n}=261)$

\begin{tabular}{lr} 
Yes & $171(65.5)$ \\
No & $90(34.5)$ \\
\hline
\end{tabular}

*Highest educational level completed.

†Including student/housewife/other.

$\ddagger$ No previous children at the time of pregnancy.

$\S U$ se after awareness of pregnancy.

INone of the respondents reported use exceeding two units/ month.

${ }^{\star *}$ Numbers do not add up due to missing data.
5 (1=strongly disagree, $2=$ disagree, $3=$ uncertain, $4=$ agree, $5=$ strongly agree). The individual total item scores ranged from 5 to 25, with higher scores indicating stronger beliefs in necessity or concerns, respectively. We also calculated the Necessity-Concerns differential, that is, the difference between the Necessity and Concerns scores. A positive difference implies that patients perceive the benefits of medication to outweigh the risks, whereas scores with a negative sign indicate the converse.

Six additional statements were designed by the authors of this study to explore beliefs about migraine and medication use during pregnancy and breastfeeding. They were designed especially for this study by the author group. They reflect our clinical experience in counselling pregnant and breastfeeding women with migraine about medications. For each statement, the women marked their level of agreement on a 5-point Likert scale ranging from 1 to 5 ( 1 =strongly disagree, $2=$ disagree, $3=$ uncertain, $4=$ agree, $5=$ strongly agree). In the analyses, responses were trichotomised into agree, disagree and uncertain.

\section{Medication adherence}

Respondents' adherence to needed migraine pharmacotherapy during pregnancy and breastfeeding period was assessed by asking, 'Have you ever, at one or several occasions, deliberately refrained from taking migraine medications because you were a) pregnant; b) breastfeeding?' (Yes/No), the latter question directed to mothers only. Respondents confirming the question(s) were asked which medication(s) they had avoided and their reason(s) for doing so.

\section{Statistical analysis}

Descriptive statistics were used to calculate the overall median and IQR of risk perception scores for each of the substances. As the risk estimates were not normally distributed, we used the non-parametric Mann-Whitney $\mathrm{U}$ test for comparison of risk estimates between pregnant women and mothers, and between users and non-users of the specified drug/substance, respectively. Non-parametric statistics were also applied for the comparison of beliefs about medicines (BMQ-Specific) between users and non-users of migraine medications during pregnancy. $P$ values $<0.05$ were considered statistically significant. All statistical analyses were performed using the Statistical Package for Social Sciences V.24.0.

\section{RESULTS}

\section{Study population}

A total of 401 women with self-reported migraine responded to the survey. Of these, 140 (34.9\%) were pregnant and $261(65.1 \%)$ had delivered within the previous 18 months. The mean age of the participants was 30.0 years (median 30, range 18-46 years). Sociodemographic, lifestyle and migraine-related characteristics of the study population are presented in table 1 . 


\section{Use of migraine medication}

In total, $294(73.3 \%)$ of the women reported use of migraine medications (both over-the-counter [OTC] and prescription drugs) during pregnancy. Paracetamol was the most commonly used agent $(266 / 401 ; 66.3 \%)$, followed by triptans $(58 / 401 ; 14.5 \%)$ (mainlysumatriptan) and NSAIDs $(30 / 401 ; 7.5 \%)$ (mainly ibuprofen). On average, the women reported use of 1.1 (median 1 , range 0-7) drugs during pregnancy. Use of herbal medicines for the treatment of migraine was reported by $46(11.5 \%)$ women. Among the new mothers, migraine pharmacotherapy during breastfeeding was reported by 171 $(65.5 \%)$. A total overview of the use of migraine medications during pregnancy and breastfeeding period has been presented in a previous publication. ${ }^{25}$ An overview of use of the migraine medications assessed by risk perception scores (paracetamol, ibuprofen, triptans, metoclopramide and herbal medicines) in pregnancy in general and during the first trimester in specific is presented in online supplementary table 1 .

\section{Risk perception}

Overall, women estimated the baseline teratogenic risk, that is, the chance of a healthy pregnant woman giving birth to a child with a severe birth defect, to be low. Of the 312 women who answered this question, 244 (78.2\%) estimated the risk of severe birth defects to occur in less than 5 of 100 births, $60(19.2 \%)$ estimated the risk to occur in 5-10 of 100 births, whereas $8(2.6 \%)$ women perceived the risk to occur in more than 10 of 100 births. A total of $89(22.2 \%)$ women did not know or left the question blank.

The teratogenic risk estimates of the 14 different drugs/substances are illustrated in figure 1 . The highest risk estimates were assigned for thalidomide, tobacco (smoking) and alcohol (in first trimester), respectively. Regarding thalidomide, only $105 / 401$ (26.2\%) women were familiar with this substance and reported a corresponding risk estimate. However, among the women who did assign a risk estimate of thalidomide, more than $70 \%$ rated it as 10 (very harmful). Overall, there were no significant differences in risk estimates between pregnant women and new mothers, with the exception of paracetamol, being ranked higher among pregnant women compared with new mothers (median [IQR] 2.0 [1.0-3.0] vs $1.0[0.0-2.0],[\mathrm{p}=0.014]$ ) (data not shown). Online supplementary table 2 presents the risk estimates for the specified migraine medications according to individual use during pregnancy, with the exception of naratriptan, of which use was not reported by any of the women during pregnancy. Risk estimates of paracetamol, ibuprofen (in third trimester), sumatriptan, zolmitriptan, rizatriptan, eletriptan and metoclopramide were significantly higher among non-users compared with users. Likewise, participants reporting use of alcohol and/or smoking during pregnancy perceived their associated risk to be significantly lower than did non-users (data not shown). Information about use of penicillins (and naturally, thalidomide) during pregnancy was not obtained in the survey and therefore not included in the comparisons.

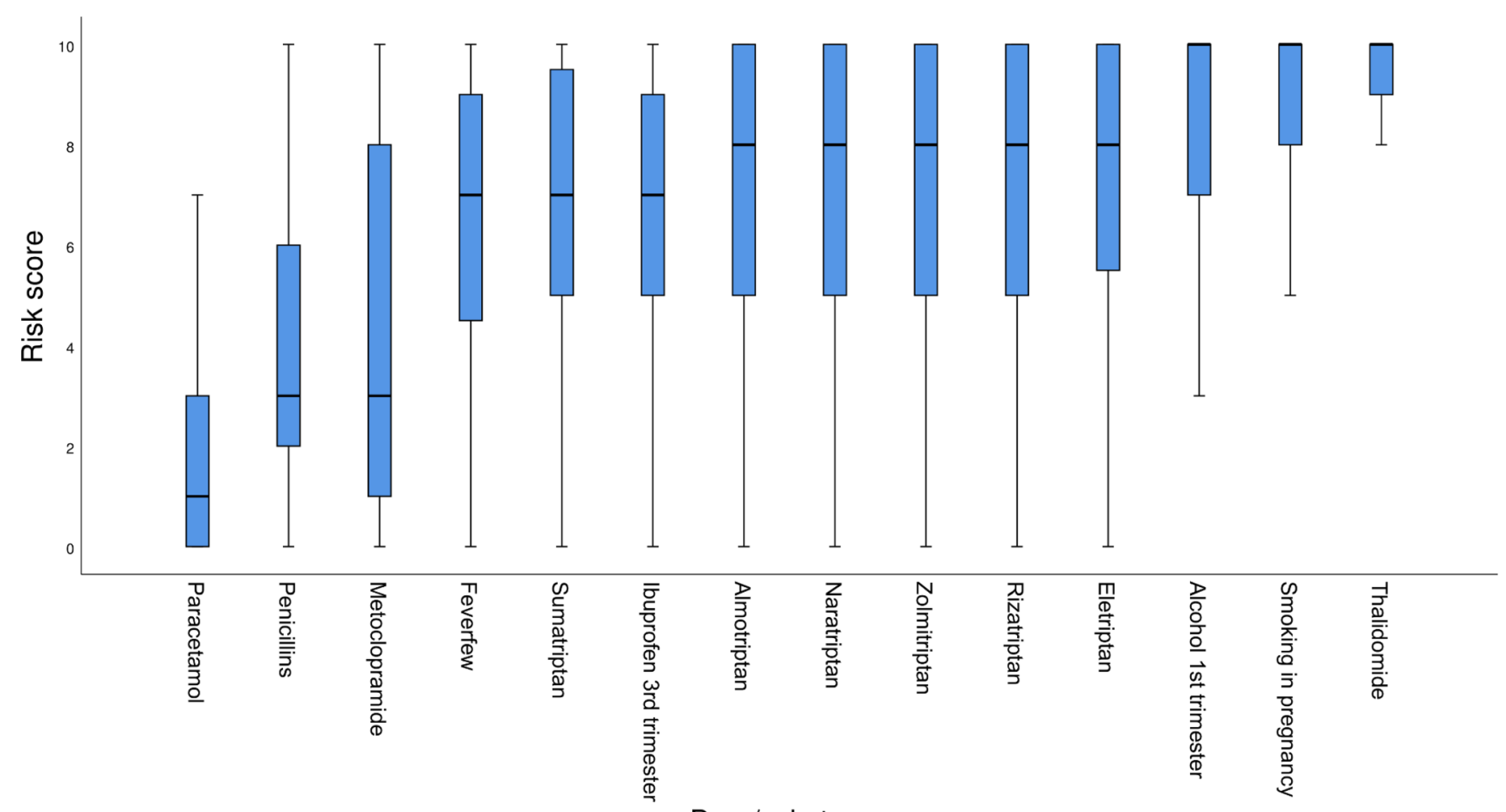

Drug/substance

Figure 1 Median teratogenic risk scores with IQR for each of the 14 drugs/substances. Risk scores were assigned in a range from 0 (not harmful to the fetus) to 10 (very harmful to the fetus). 


\begin{tabular}{|c|c|c|c|}
\hline $\begin{array}{l}\text { BMQ-Specific } \\
\text { statements* }^{*}\end{array}$ & $\begin{array}{l}\text { \% Agree/ } \\
\text { strongly } \\
\text { agree }\end{array}$ & $\begin{array}{l}\text { \% Disagree/ } \\
\text { strongly } \\
\text { disagree }\end{array}$ & $\begin{array}{l}\% \\
\text { Uncertain }\end{array}$ \\
\hline \multicolumn{4}{|l|}{ Necessity } \\
\hline $\begin{array}{l}\text { My health, at } \\
\text { present, depends } \\
\text { on my medicines. }\end{array}$ & 29.4 & 55.6 & 15.0 \\
\hline $\begin{array}{l}\text { My life would } \\
\text { be impossible } \\
\text { without my } \\
\text { medicines. }\end{array}$ & 40.1 & 38.7 & 21.2 \\
\hline $\begin{array}{l}\text { Without my } \\
\text { medicines I would } \\
\text { be very ill. }\end{array}$ & 42.9 & 34.4 & 22.7 \\
\hline $\begin{array}{l}\text { My health in the } \\
\text { future will depend } \\
\text { on my medicines. }\end{array}$ & 35.4 & 32.7 & 31.9 \\
\hline $\begin{array}{l}\text { My medicines } \\
\text { protect me from } \\
\text { becoming worse. }\end{array}$ & 33.2 & 31.7 & 35.2 \\
\hline \multicolumn{4}{|l|}{ Concerns } \\
\hline $\begin{array}{l}\text { Having to take my } \\
\text { medicines worries } \\
\text { me. }\end{array}$ & 58.9 & 26.7 & 14.5 \\
\hline $\begin{array}{l}\text { I sometimes worry } \\
\text { about the long } \\
\text { term effects of my } \\
\text { medicines. }\end{array}$ & 46.9 & 31.9 & 21.2 \\
\hline $\begin{array}{l}\text { My medicines are } \\
\text { a mystery to me. }\end{array}$ & 16.2 & 52.9 & 30.9 \\
\hline $\begin{array}{l}\text { My medicines } \\
\text { disrupt my life. }\end{array}$ & 16.2 & 63.3 & 20.5 \\
\hline $\begin{array}{l}\text { I sometimes worry } \\
\text { about becoming } \\
\text { too dependent on } \\
\text { my medicines. }\end{array}$ & 23.9 & 63.6 & 12.5 \\
\hline
\end{tabular}

*The BMQ-Specific is copyrighted (Professor Rob Horne). $\mathrm{BMQ}$, Beliefs about Medicines Questionnaire.

Concerning feverfew, we did not ask specifically about use of this substance in the questionnaire; therefore, we compared risk perception of feverfew between non-users and users of herbal medicines in general. In terms of absolute differences, the largest differences in median risk estimates were found for triptans. Sumatriptan was perceived as relatively safer than the other triptans.

\section{Beliefs about migraine medication}

Table 2 shows the responses for each of the BMQ-Specific statements for the total study population, and table 3 compares the median and IQR of the total BMQ-Necessity and BMQ-Concerns scores and the Necessity-Concerns differential between users and non-users of migraine medications during pregnancy, respectively. Women who reported use of migraine medication during pregnancy had significantly higher Necessity-Concerns differential scores compared with non-users, indicating that they more strongly considered the benefits of medical treatment to outweigh the risks (table 3 ). The women's beliefs about migraine and migraine medications during pregnancy/breastfeeding period are presented in table 4 .

\section{Medication adherence}

A total of $350 / 401$ (87.3\%) women confirmed that they at one or several occasions deliberately had refrained from taking needed migraine medications because they were pregnant. Among the mothers who answered the corresponding question concerning medication use postpartum $(\mathrm{n}=259), 161(62.2 \%)$ had at one or several occasions decided not to take migraine medications because they were breastfeeding. Triptans were the medication group that most women reported to avoid, both in pregnancy $(200 / 350,57.1 \%)$ and during the breastfeeding period $(95 / 161,59.0 \%)$. Other migraine medications frequently avoided were NSAIDs and paracetamol. The main reasons given for not wanting to take medications was fear of harming the unborn child and/or breastfed infant, recommendations from their doctor or other healthcare professionals and information from other sources (eg, internet and family/friends) about potential harmful effects. Some women had previously experienced a negative pregnancy outcome (ie, spontaneous abortion), which impacted on their decision not to use medicines in their current pregnancy. A representative selection of citations from the study participants concerning migraine medication and adherence of therapy during pregnancy and breastfeeding is presented in table 5 .

\section{DISCUSSION}

To our knowledge, this is the first study to explore risk perception, beliefs about migraine medications and medical adherence in pregnant and breastfeeding women with migraine. The results indicate that the perceived risk associated with migraine pharmacotherapy in pregnancy is highly overestimated among women with migraine. Although use of migraine medication was common in our study population, most of the women expressed concern about using such medicines during pregnancy and postpartum. Almost 9 out of 10 women had at one or several occasions deliberately refrained from using migraine medication during pregnancy despite a perceived need for medication. Equivalently, more than half of the mothers reported occasional non-adherence to needed treatment during the breastfeeding period.

A particular strength of this study is its focus on women's own perspectives on the management of migraine during pregnancy and breastfeeding. We used a validated instrument to measure patients' beliefs about medicines, and we assessed a number of sociodemographic, health-related and medicine-related factors. Increased awareness of women's concerns and informational needs may help 
Table 3 Beliefs about medicines according to use of migraine medication during pregnancy $(n=401)$

\begin{tabular}{|c|c|c|c|c|c|c|c|}
\hline Beliefs about medicines & \multicolumn{2}{|c|}{$\begin{array}{l}\text { Total study } \\
\text { population } \\
(n=401)\end{array}$} & \multicolumn{2}{|c|}{$\begin{array}{l}\text { Use of migraine } \\
\text { medication } \\
(n=294)\end{array}$} & \multicolumn{2}{|c|}{$\begin{array}{l}\text { No use of migraine } \\
\text { medication } \\
(n=107)\end{array}$} & $\begin{array}{l}\text { Use versus no use } \\
\text { of medication } \\
\text { P value } \\
\text { (Mann-Whitney) }\end{array}$ \\
\hline \multicolumn{8}{|l|}{ BMQ-Specific* } \\
\hline Necessity & 15 & $6-24$ & 16 & $9-23$ & 12 & $4-20$ & $<0.001$ \\
\hline $\begin{array}{l}\text { Necessity-Concerns } \\
\text { differential }\end{array}$ & 0 & -6 to 6 & 1 & -5 to 7 & -1 & -8 to 6 & 0.003 \\
\hline
\end{tabular}

${ }^{*}$ The BMQ-Specific questionnaire comprises the BMQ-Necessity and BMQ-Concerns subscales (total score range 5-25). Higher scores indicate stronger beliefs in the concepts of the subscale. The Necessity-Concerns differential is the difference between the BMQ-Necessity and the BMQ-Concerns scores (a positive difference implies that patients perceive the benefits of medication to outweigh the risks, whereas scores with a negative sign indicate the converse).

The BMQ-Specific is copyrighted (Professor Rob Horne)

$\mathrm{BMQ}$, Beliefs about Medicines Questionnaire.

healthcare professionals to better understand the impact of the disease and how to improve healthcare to this patient group. There are, however, several limitations to this study that need to be considered when interpreting the results. The questionnaire was only available through internet websites, which did not enable us to calculate a conventional response rate. Moreover, studies using electronic questionnaires carry a potential risk of selection bias towards the more literate population. Nevertheless, recent epidemiological studies indicate adequate validity of internet-based recruitment methods. ${ }^{28}{ }^{29}$ Also, the internet penetration rate, either in households or at work, is high among Norwegian women of reproductive age; national statistics from the year the survey was conducted showed that $97 \%$ of women aged 16-44 years reported use of internet on a daily basis. ${ }^{30}$ Additionally, using the internet for recruitment and data collection enabled us to reach women with migraine nationwide, including all health regions of the country. Another limitation of the study is the self-report of data, relying on the women's accuracy of recall. Moreover, we did not use a validated measure of medication adherence. We did not differentiate between one-time or repeated avoidance of medications, and were thus not able to differentiate between low, moderate and high levels of adherence. Overall, our study sample is largely comparable to the population of other studies conducted among Norwegian female migraineurs of reproductive age with respect to age, marital status, parity, life-style habits and level of education. ${ }^{5}{ }^{6}$ However, consistent with most questionnaire-based studies, our study participants had, on average, a higher level of education compared with the general female population of reproductive age in Norway. ${ }^{31}$ Higher level of education has previously been associated with higher teratogenic risk perception, ${ }^{14}$ and our findings may therefore be an overestimation of risk perception in general. These factors must be taken into account when interpreting the results, as they may limit the generalisability of our findings.

Overall, the majority of the women in our study $(>60 \%)$ correctly estimated the baseline risk of severe birth defects in the general population $(<5 \%)$, which

Table 4 Women's beliefs about migraine and migraine medications during pregnancy and breastfeeding period $(n=401)$

\begin{tabular}{llcc}
\hline Statements $^{*}$ & \% Agree & \% Disagree & \% Uncertain \\
\hline I feared that my migraine would get worse during pregnancy ( $n=383)$. & 83.0 & 11.5 & 5.5 \\
$\begin{array}{l}\text { I used less migraine medication than needed due to the fact that I was pregnant } \\
\text { ( } n=310) .\end{array}$ & 85.2 & 11.0 & 3.9 \\
\hline I was worried that my migraine medication might affect my unborn child ( $n=301)$. & 89.7 & 7.0 & 3.3 \\
$\begin{array}{l}\text { In my experience, my doctor had sufficient knowledge of the usage of } \\
\text { medications during pregnancy ( } n=345) .\end{array}$ & 40.3 & 33.0 & 26.7 \\
$\begin{array}{l}\text { Even if I suffered a migraine attack during pregnancy, I refrained from taking any } \\
\text { medication, just to be on the safe side ( } n=351) \text {. }\end{array}$ & 82.9 & 13.1 & 4.0 \\
$\begin{array}{l}\text { I am unsure whether breastfeeding is safe while taking migraine medications } \\
\text { ( } n=338) .\end{array}$ & 71.3 & 14.8 & 13.9
\end{tabular}

*Number of women responding to each statement in parentheses. Respondents answering 'Does not apply to me' are treated as missing values. 
Table 5 Selected citations from the study participants concerning migraine medication and adherence of therapy during pregnancy and breastfeeding*

Pregnancy 'For me, it was absolutely out of the question to take such strong medications while pregnant. But it was tough and I was extremely ill'.

(Mother, 35years, refraining from use of triptans and NSAIDs during pregnancy)

'I was afraid it would harm by baby. My doctor discouraged me from taking any migraine medications while pregnant if I could manage without it, so I did. He recommended sick-leave before use of medications so I have been on sick-leave from week 10'.

(Pregnant woman, 32 years, refraining from use of sumatriptan, paracetamol and ibuprofen during pregnancy)

'I didn't want to take any risks, even if there might be no reason to be worried. I felt that my doctor had little knowledge about the issue'.

(Mother, 32 years, refraining from use of diclofenac during pregnancy)

'I have had several spontaneous miscarriages, and I feared that something might happen to my baby'. (Pregnant woman, 23 years, refraining from use of paracetamol/codeine during pregnancy)

' I didn't want to expose my child for any potential drug effects. However, I didn't understand that my physical health condition during an attack might have negative effects as well'.

(Pregnant woman, 29years, refraining from use of rizatriptan during pregnancy)

Breastfeeding 'I just assumed it would still be dangerous, as I was discouraged from using it during pregnancy'.
(Mother, 27 years, refraining from use of ibuprofen during breastfeeding)
'I initiated breastfeeding for a week, and pumped and discarded milk for 12 hours after taking a tablet. So I
soon discontinued breastfeeding because of this'.
(Mother, 22 years, discontinuing breastfeeding because of use of sumatriptan)

${ }^{*}$ The citations constitute a representative selection of statements from study participants confirming the following question(s): 'Have you ever, at one or several occasions, deliberately refrained from taking migraine medications because you were a) pregnant; b) breastfeeding?'. NSAIDs, non-steroidal anti-inflammatory drugs.

correlate with findings from previous studies assessing risk perception related to medication exposure in pregnancy. ${ }^{14}$ Not unexpectedly, thalidomide, tobacco (smoking) and alcohol were the substances perceived to be the most harmful, which is also similar to findings from other studies. ${ }^{14}{ }^{15}$ The tragedy of thalidomide in the early $1960 \mathrm{~s}^{32}$ led to an increased public awareness of the potential harmful effects associated with maternal medication use in pregnancy. Nevertheless, a surprisingly low proportion (only 26\%) of the women in this study were familiar with thalidomide and rated it by risk perception scores, possibly indicating that the general awareness of thalidomide and its teratogenic potential is declining. This tendency has also been observed in a previous study. ${ }^{15}$ The potential harmful effects of smoking (risk of low infant birth weight and premature birth) and use of alcohol (risk of fetal alcohol syndrome) during pregnancy are well documented, and government policies advise all pregnant women to completely abstain from use. Noticeably, those participants reporting use of alcohol and/or smoking during pregnancy perceived their associated risk to be significantly lower than non-users. Of the migraine medications assessed by risk perception scores, women rated paracetamol as the safest, which is in line with current treatment recommendations. We were concerned that recent findings indicating increased risk of neurodevelopmental effects with prolonged use of paracetamol during pregnancy ${ }^{33}$ may have affected risk perception of short-term use, such as in treatment of migraine attacks. The fact that women with migraine perceived the risk of paracetamol use to be low is reassuring.

Triptans, however, being the most commonly used migraine-specific agents, were overall given unrealistically high risk estimates. This correlates with the finding that triptans were the medications that most women reported to avoid in pregnancy. Noteworthy, sumatriptan was perceived as relatively safer to use during pregnancy than the other agents in this medication group. This perception might be influenced by current prescribing practice, as sumatriptan is often considered the first choice if treatment with triptans is considered necessary in pregnancy, owing to the longest clinical experience with use in pregnant women. Findings from published studies on triptan use during pregnancy are reassuring. One large population-based study did not observe that triptan therapy during pregnancy was associated with an overall increased risk of congenital malformations. ${ }^{35}$ Overall, reported risk estimates of paracetamol, ibuprofen, sumatriptan, zolmitriptan, rizatriptan, eletriptan and metoclopramide were significantly higher among non-users compared with users of the respective substances. This finding implies that perceived risk of medication use may influence the decision for whether to use a medication. Women perceiving migraine medications as more harmful may be more reluctant to use during pregnancy even if they experience a migraine attack that requires treatment.

Those women reporting use of migraine medication during pregnancy expressed more positive attitudes 
towards medications, and they more strongly considered the benefit of their medicines to outweigh the risk, as demonstrated by the higher BMQ Necessity-Concerns differential scores compared with non-users. Nevertheless, when the women were asked specifically about their concerns related to fetal drug exposure, 9 out of 10 women confirmed that they had worried whether their migraine medications might affect their unborn child (table 4). Overall, this was the most commonly given reason for not adhering to needed treatment. Many women stated that they would rather suffer a migraine attack untreated than to take any risks, however small they might be. Some women had previously experienced a negative pregnancy outcome (ie, miscarriage), which influenced their decisions to abstain from medications in their current pregnancy. It was also evident that women had concerns about medicines and breastfeeding. Of the women responding to the statement 'I am unsure whether breastfeeding is safe while taking migraine medications', more than $70 \%$ agreed or strongly agreed to the statement. A few women even reported that they discontinued breastfeeding because they were taking medications and feared the consequences of exposing their infant to potential drug effects. This illustrates the need for more available and consistent information to pregnant and breastfeeding women about the safety of their medicines.

Considering the high prevalence of migraine among women of childbearing age and the high proportion of women reporting use of migraine medications during pregnancy and breastfeeding, more attention should be focused on the quality of healthcare provided to this patient group. Our study clearly illustrates the need for adequate and individually tailored counselling of women in how to manage their disease during pregnancy and breastfeeding period. Counselling should address the expected course of migraine throughout pregnancy and postpartum, provide weighted information about the benefit and potential risk of current medical treatment and consider alternative treatment options if necessary. Issues related to medical treatment should preferably be addressed before pregnancy is contemplated and ought to be an integrated part of maternity care visits. More effort should be made to actively involve women themselves in making decisions about medication use to promote adherence to needed treatment during pregnancy and breastfeeding. Continual assessment of disease activity and need for medication can be managed by keeping a headache diary and may aid in the communication between the patient and her healthcare provider. Moreover, a standardised assessment will secure early identification of women with special needs who may require closer follow-up in pregnancy. If necessary, one should consider referring the woman to specialist services (ie, neurologist). Enhanced collaboration and communication between midwives, general practitioners and community pharmacists is important, as they fulfil complementary roles as care givers and providers of information. Healthcare professionals should actively question women's beliefs and concerns about their medicines in order to clarify any misconceptions and possibly reduce unfounded concerns and promote adherence to prescribed therapy. In this respect, the community pharmacist in particular, plays an important role, being a highly qualified and easily accessible healthcare professional outside regular maternity check-ups. Furthermore, the pharmacist is often in direct contact with the woman when she obtains her prescription for migraine medication, or purchases OTC analgesics, and should take this opportunity to counsel about medication use and safety. ${ }^{36}$

Further studies are called for to evaluate the quality of healthcare provided to women with migraine of childbearing age and how their informational needs on safe medication use are met by doctors, pharmacists, midwives and other healthcare personnel involved in maternity care. Suggestions for future research also include exploring physicians' perception of teratogenic risk and their confidence in prescribing migraine medications to pregnant and breastfeeding women.

\section{CONCLUSIONS}

Many women with migraine severely overestimate the risk associated with migraine pharmacotherapy in pregnancy. A substantial proportion of the women in this study reported deliberate non-adherence to needed treatment during pregnancy and breastfeeding period in fear of harming their child. These findings underline the need for more available and consistent information to the public about migraine medication use during pregnancy and breastfeeding. Understanding women's perceptions of the risk and benefit of medical treatment is essential for healthcare providers to promote optimal management of migraine during and after pregnancy, reduce unfounded concerns and enhance medication adherence.

Acknowledgements The authors would like to thank all the women who participated in the study. We would also like to thank Professor Rob Horne for granting permission to use the Beliefs about Medicines Questionnaire (BMQ). The publication charges for this article have been funded by a grant from the publication fund of UiT The Arctic University of Norway.

Contributors HN initiated the study and compiled the study team. HN and SA wrote the study protocol and obtained the required approvals. NMSA, SA, HN and TGØ designed and piloted the questionnaire. NMSA and TGØ were responsible for actively promoting the study and recruiting participants through social media. SA conducted the analyses of the data and drafted the manuscript. HN supervised the data analyses and interpretation of the data and contributed to revisions of the manuscript with important intellectual content. ACP assisted in development of the questionnaire and provided comments for revision of the manuscript. All authors read and approved the final version of the manuscript. SA is the guarantor for this paper.

Funding SA is funded through a research grant from the Northern Norway Regional Health Authority (Project ID: SFP1248-15).

Competing interests All authors have completed the Unified Competing Interest form at http://www.icmje.org/coi_disclosure.pdf (available on request from the corresponding author). ACP has given lectures and presentations for Allergan, GlaxoSmithKline, MSD, Novartis, Nycomed and Pfizer from 1999 to 2018 and has occasionally participated in advisory boards for Allergan, Novartis, Nycomed and GlaxoSmithKline. She currently works in a private specialist headache clinic offering outpatient treatment. 
Patient consent for publication Not required.

Ethics approval All participants gave informed consent by answering 'Yes' to the question, 'Are you willing to participate in the study?'. The study was approved by the Regional Ethics Committee, Region North in Norway (2013/1193). All data were handled and stored anonymously.

Provenance and peer review Not commissioned; externally peer reviewed.

Data sharing statement № additional data are available. Researchers can apply for data access for subprojects within the overall aims of the MIMEGA study by contacting the primary investigator: Professor Hedvig Nordeng; h.m.e.nordeng@ farmasi.uio.no.

Open access This is an open access article distributed in accordance with the Creative Commons Attribution Non Commercial (CC BY-NC 4.0) license, which permits others to distribute, remix, adapt, build upon this work non-commercially, and license their derivative works on different terms, provided the original work is properly cited, appropriate credit is given, any changes made indicated, and the use is non-commercial. See: http://creativecommons.org/licenses/by-nc/4.0/.

\section{REFERENCES}

1. Stovner LJ, Zwart JA, Hagen $\mathrm{K}$, et al. Epidemiology of headache in Europe. Eur J Neurol 2006;13:333-45.

2. Allais G, Rolando S, De Lorenzo C, et al. Migraine and pregnancy: an internet survey. Neurol Sci 2013;34 (Suppl 1):S93-9.

3. Sances G, Granella F, Nappi RE, et al. Course of migraine during pregnancy and postpartum: a prospective study. Cephalalgia 2003;23:197-205.

4. Kvisvik EV, Stovner LJ, Helde G, et al. Headache and migraine during pregnancy and puerperium: the MIGRA-study. J Headache Pain 2011:12:443-51.

5. Nezvalová-Henriksen K, Spigset O, Nordeng H. Maternal characteristics and migraine pharmacotherapy during pregnancy: cross-sectional analysis of data from a large cohort study. Cephalalgia 2009;29:1267-76.

6. Harris GE, Wood M, Eberhard-Gran M, et al. Patterns and predictors of analgesic use in pregnancy: a longitudinal drug utilization study with special focus on women with migraine. BMC Pregnancy Childbirth 2017;17:224.

7. Evers S, Afra J, Frese A, et al. EFNS guideline on the drug treatment of migraine-revised report of an EFNS task force. Eur $\mathrm{J}$ Neurol 2009:16:968-81.

8. Worthington I, Pringsheim T, Gawel MJ, et al. Canadian Headache Society Guideline: acute drug therapy for migraine headache. Can J Neurol Sci 2013;40(Suppl 3):S1-S80.

9. Nordeng H, Koren G, Einarson A. Pregnant women's beliefs about medications-a study among 866 Norwegian women. Ann Pharmacother 2010;44:1478-84.

10. Twigg MJ, Lupattelli A, Nordeng $\mathrm{H}$. Women's beliefs about medication use during their pregnancy: a UK perspective. Int J Clin Pharm 2016;38:968-76.

11. Lupattelli A, Spigset $O$, Björnsdóttir I, et al. Patterns and factors associated with low adherence to psychotropic medications during pregnancy-a cross-sectional, multinational web-based study. Depress Anxiety 2015;32:426-36.

12. Lynch MM, Squiers LB, Kosa KM, et al. Making decisions about medication use during pregnancy: Implications for communication strategies. Matern Child Health J 2018;22:92-100.

13. Moore KL, Persaud TVN, Torchia MG. The developing human: clinically oriented embryology. 10th ed: Elsevier, 2016.

14. Nordeng H, Ystrøm E, Einarson A. Perception of risk regarding the use of medications and other exposures during pregnancy. Eur J Clin Pharmacol 2010;66:207-14.

15. Petersen I, McCrea RL, Lupattelli A, et al. Women's perception of risks of adverse fetal pregnancy outcomes: a large-scale multinational survey. BMJ Open 2015;5:e007390.
16. Widnes SF, Schjøtt J, Eide GE, et al. Teratogenic risk perception and confidence in use of medicines in pairs of pregnant women and general practitioners based on patient information leaflets. Drug Saf 2013;36:481-9.

17. Kaplan YC, Karadaș B, Küçüksolak G, et al. Counselling pregnant women at the crossroads of Europe and Asia: effect of Teratology Information Service in Turkey. Int J Clin Pharm 2017;39:783-90.

18. Sanz E, Gómez-López T, Martínez-Quintas MJ. Perception of teratogenic risk of common medicines. Eur J Obstet Gynecol Reprod Biol 2001:95:127-31.

19. Pole M, Einarson A, Pairaudeau N, et al. Drug labeling and risk perceptions of teratogenicity: a survey of pregnant Canadian women and their health professionals. J Clin Pharmacol 2000;40:573-7.

20. Csajka C, Jaquet A, Winterfeld U, et al. Risk perception by healthcare professionals related to drug use during pregnancy: a Swiss survey. Swiss Med Wkly 2014;144:w13936.

21. Cantilino A, Lorenzo L, Paula JA, et al. Use of psychotropic medications during pregnancy: perception of teratogenic risk among physicians in two Latin American countries. Braz J Psychiatry 2014;36:106-10.

22. Walfisch A, Sermer C, Matok I, et al. Perception of teratogenic risk and the rated likelihood of pregnancy termination: association with maternal depression. Can J Psychiatry 2011;56:761-7.

23. Einarson A, Selby P, Koren G. Abrupt discontinuation of psychotropic drugs during pregnancy: fear of teratogenic risk and impact of counselling. J Psychiatry Neurosci 2001;26:44-8.

24. Bonari L, Koren G, Einarson TR, et al. Use of antidepressants by pregnant women: evaluation of perception of risk, efficacy of evidence based counseling and determinants of decision making. Arch Womens Ment Health 2005;8:214-20.

25. Amundsen S, Øvrebø TG, Amble NM, et al. Use of antimigraine medications and information needs during pregnancy and breastfeeding: a cross-sectional study among 401 Norwegian women. Eur J Clin Pharmacol 2016;72:1525-35.

26. Schaefer $\mathrm{C}$, Peters P, Miller RK, et al. Drugs during pregnancy and lactation. Treatment options and risk assessment. 3rd ed. London: Academic Press, 2015.

27. Horne R, Weinman J, Hankins M. The beliefs about medicines questionnaire: The development and evaluation of a new method for assessing the cognitive representation of medication. Psychol Health 1999;14:1-24.

28. Ekman A, Dickman PW, Klint A, et al. Feasibility of using web-based questionnaires in large population-based epidemiological studies. Eur J Epidemiol 2006;21:103-11.

29. van Gelder MM, Bretveld RW, Roeleveld N. Web-based questionnaires: the future in epidemiology?. Am J Epidemiol 2010;172:1292-8.

30. Norwegian Media Barometer. Table 04519: Percentage internet users and minutes used for internet an average day, by sex and education. Statistics Norway; 2014. https://www.ssb.no/statistikkbanken (accessed 04 Jan 2018)

31. StatBankNorway. Table 08921: Persons 16 years and older, by sex, age and level of education. Numbers and percent (C). Statistics Norway; 2014. https://www.ssb.no/statistikkbanken (accessed 04 Jan 2018).

32. McBride WG. Thalidomide and congenital malformations. Letter to the editor. Lancet 1961;2:1358.

33. Liew Z, Ritz B, Rebordosa C, et al. Acetaminophen use during pregnancy, behavioral problems, and hyperkinetic disorders. JAMA Pediatr 2014;168:313-20.

34. Brandlistuen RE, Ystrøm E, Nulman I, et al. Prenatal paracetamol exposure and child neurodevelopment: a sibling-controlled cohort study. Int J Epidemiol 2013;42:1702-13.

35. Nezvalová-Henriksen $\mathrm{K}$, Spigset $\mathrm{O}$, Nordeng H. Triptan exposure during pregnancy and the risk of major congenital malformations and adverse pregnancy outcomes: results from the Norwegian Mother and Child Cohort Study. Headache 2010;50:563-75.

36. Ceulemans M, Lupattelli A, Nordeng $\mathrm{H}$, et al. Women's beliefs about medicines and adherence to pharmacotherapy in pregnancy: opportunities for community pharmacists? A narrative review. Curr Pharm Des. In Press. 